\title{
Late Relapse of Acute Myeloid Leukemia
}

National Cancer Institute

\section{Source}

National Cancer Institute. Late Relapse of Acute Myeloid Leukemia. NCI Thesaurus. Code C123404.

Clinical and/or laboratory evidence of reemergence of acute myeloid leukemia greater than or equal to 12 months from diagnosis. 